\title{
Surveillance, anticipation and firefighting: Perspectives of patient safety from a New Zealand case study
}

\author{
Jo Wailling ${ }^{1}$ (D) | Brian Robinson ${ }^{1}$ (i) | Maureen Coombs ${ }^{1,2}$ (i)
}

${ }^{1}$ Faculty of Health, Victoria University of Wellington, Wellington Regional Hospital, Wellington, New Zealand

${ }^{2}$ School of Nursing and

Midwifery, University of Plymouth,

Plymouth, UK

\section{Correspondence}

Jo Wailling, Graduate School of Nursing, Midwifery \& Health, Faculty of Health, Victoria University of Wellington, Wellington Regional Hospital, Wellington, New Zealand.

Email: jo.wailing@vuw.ac.nz

\begin{abstract}
Aim: This study explored how doctors, nurses and managers working in a New Zealand tertiary hospital understand patient safety.

Background: Despite health care systems implementing proven safety strategies from high reliability organisations, such as aviation and nuclear power, these have not been uniformly adopted by health care professionals with concerns raised about clinician engagement.

Design: Instrumental, embedded case study design using qualitative methods.

Methods: The study used purposeful sampling, and data was collected using focus groups and semi-structured interviews with doctors $(n=31)$; registered nurses $(n=19)$; and senior organisational managers $(n=3)$ in a New Zealand tertiary hospital.

Results: Safety was described as a core organisational value. Clinicians appreciated proactive safety approaches characterized by anticipation and vigilance, where they expertly recognized and adapted to safety risks. Managers trusted evidence-based safety rules and approaches that recorded, categorized and measured safety.

Conclusion and Implications for Nursing Management: It is important that nurse managers hold a more refined understanding about safety. Organisations are more likely to support safe patient care if cultural complexity is accounted for. Recognizing how different occupational groups perceive and respond to safety, rather than attempting to reinforce a uniform set of safety actions and responsibilities, is likely to bring together a shared understanding of safety, build trust and nurture safety culture.
\end{abstract}

KEYWORDS

acute care, leadership, patient safety, safety culture, safety systems

\section{1 | INTRODUCTION}

The World Health Organization (2018) estimates that one in 10 patients will experience harm resulting from health care. The international scale of patient harm is apparent in the stream of "watershed" public investigations that report preventable patient deaths (Department of Health, 2013; Kohn, Corrigan, \& Donaldson, 2000; National Patient Safety Foundation, 2017; Queensland Public Hospitals Commission of Inquiry \& Davies, 2005). In response, international strategies have been put in place to reduce health care harm by implementing safety methods from high reliability organisations (HROs) such as those found in aviation and nuclear power (Sutcliffe, 2011).

\section{BACKGROUND}

Implementing HRO safety systems, such as incident reporting and protocols, has dominated health care policy with proliferation of 
safety tools including targets, quality improvement metrics and root cause analysis (RCA). However, the sentinel patient safety inquiry into Mid-Staffordshire Hospital in the United Kingdom concluded that patient safety efforts should move from outcome-based performance measures and focus on "major cultural change, rather than a new regulatory regime" (Department of Health, 2013, p. 11). Consequently, governments, regulators and quality improvement bodies swiftly embraced additional HRO strategies intended to transform safety culture such as checklists, crew resource management and leadership walk rounds (e.g., Institute of Healthcare Improvement, 2016; National Patient Safety Foundation, 2015).

Researchers have reported the relationship between patient harm and multiple variables in health care organisations, including nurse-patient ratios, human factors and culture (e.g., Atkin et al., 2014; Carayon, 2012; Vaugh et al., 2018). A systematic review by Braithwaite, Herkes, Ludlow, Testa, and Lamprell (2017) identified a positive association between culture, almost exclusively measured by surveys, and patient safety outcomes. However, low survey response rates, particularly from doctors (Scott et al., 2011), questions construct validity of current surveys, and the assumption that safety culture is comparable in different parts of organisations. Qualitative work has successfully explored and identified safety subcultures (Dixon-Woods, Suokas, \& Tarrent, 2009; Hardy, 2013) although little is known about how subcultures impact safety culture (Manion \& Smith, 2017).

New Zealand (NZ), like other countries, has developed a focus on mitigating harm in acute care hospitals (e.g., Health Quality Safety Commission, 2018; Ministry of Health, 2018). This has resulted in the adoption of selective HRO system approaches including national adverse events reporting (Health Quality Safety Commission, 2017). However, there is evidence these approaches have not been widely embraced nor adopted by NZ health care professionals (Hardy, 2013; Martin, Mason, Lovelock, Cumming, \& Hider, 2015). To understand why this may be, it is necessary to explore how doctors, nurses and managers in NZ perceive patient safety in their everyday work.

This New Zealand-based study therefore aimed to: (a) explore the concept of patient safety from the perspective of doctors, nurses and senior managers; and (b) describe the factors doctors, nurses and senior managers perceived to be important in a patient safety culture.

\section{1 | Research design and methods}

The study utilized instrumental, embedded case study design using qualitative methods to contextualize the phenomenon of patient safety in a NZ acute care hospital (Stake, 2005). Perceptions of patient safety held by senior organisational managers, doctors and nurses were explored and we selected the emergency department (ED) and intensive care unit (ICU) as embedded cases (Yin, 2009). These units can be identified as high-risk, high-hazard areas (Sutcliffe, 2011) that utilized organisational and locally developed safety monitoring systems and processes.

\section{2 | Study sample}

The study was undertaken in a tertiary hospital responsible for providing acute and elective care and specialist services across a large geographical area in New Zealand. Tertiary services were provided to approximately one million people across urban, rural and remote areas. Within the organisation, an Executive Director took accountability for quality, patient safety and compliance. Safety procedures were designed in accordance with national and organisational guidelines. All staff were required to report events in an electronic reporting system. All events were categorized by a charge nurse manager (CNM) and medical lead in each area. Risks that could not be mitigated by a local unit or divisional governance boards were escalated to the executive leadership team and then to hospital board members.

The ED was a dedicated trauma centre with other attendances attributable to both severe illness and minor injuries. During the period fieldwork was conducted, approximately 130 patients self-presented or were referred by another service every day. On arrival, triage scores, derived from international standards, were assigned by nurses to patients. This score indicated the severity of a patient's condition and informed whether the patient was admitted directly to the ED clinical area or returned to the waiting room.

The ICU operated within a "closed model;" that is, only the consultant on-call had admission rights to the unit. Patients were admitted from inpatient wards, operating theatres and a flight retrieval service. An early warning score (EWS) was used to identify deteriorating ward patients and prescribed a graded response within a defined time frame, including review by specially trained ICU nurses. The hospital's emergency rapid response team attended all medical emergency team (MET) calls, led by the ICU specialist registrar.

\section{3 | Data collection}

Data was collected between October 2015 and April 2016 through use of focus groups, interviews and field notes. Focus groups were identified as the best strategy to collect data from doctors and nurses (Rubin \& Rubin, 2012), during planned development days. Face-to-face interviews were conducted with senior managers, who had previously held clinical roles, in order to provide an opportunity for candid discussion (Ybema, Yanow, Wels, \& Kamsteeg, 2009). A template developed from the literature guided semi-structured, audio recorded interviews held in a private room. Two broad questions were asked: (a) can you describe what patient safety looks like in your daily practice; and (b) what organisational and clinical factors are required to develop a culture that supports patient safety? Additional probes were used to further explore responses. Six focus groups and three face-to-face interviews were conducted with a duration of 20-70 min. Fifty-three staff participated in the study (Table 1). 
TABLE 1 Participants

\begin{tabular}{|c|c|c|c|c|}
\hline Professional group & Definition & Code (n) & $\begin{array}{l}\text { Number of } \\
\text { participants }\end{array}$ & $\begin{array}{l}\text { Years of } \\
\text { experience } \\
\text { (mean) }\end{array}$ \\
\hline ED senior doctors (focus group 1 ) & Senior medical officer or registrar in training & $\operatorname{EDSDR}(n)$ & 12 & 15.9 \\
\hline ED senior doctors (focus group 2) & Senior medical officer or registrar in training & $\operatorname{EDSDR}(n)$ & 12 & 15.9 \\
\hline ED senior nurses & $\begin{array}{l}\text { Registered nurse with formally designated leadership } \\
\text { role in staff management, education, clinical } \\
\text { expertise or research }\end{array}$ & $\operatorname{EDSRN}(n)$ & 7 & 13.7 \\
\hline ED registered nurses & Registered nurse & $\operatorname{EDRN}(n)$ & 6 & 2.8 \\
\hline ICU senior doctors & Senior medical officers and registrars in training & ICUSDR (n) & 7 & 15 \\
\hline ICU nurses & $\begin{array}{l}\text { Registered nurse with formally designated leadership } \\
\text { role in staff management, education, clinical } \\
\text { expertise or research }\end{array}$ & ICUSRN (n) & 6 & 15 \\
\hline Senior manager & Executive, professional or operational leadership role & $\mathrm{SM}(n)$ & 3 & Not providec \\
\hline
\end{tabular}

TABLE 2 Strategies for case study rigour

$\begin{array}{ll}\text { Criterion } & \text { Strategies } \\ \text { Reliability } & \text { - Case study protocol detailed } \\ & \text { - Interview guide developed } \\ & \text { - Formal database recording transcripts, excel sheets and diagrammatic } \\ & \text { representations kept } \\ \text { Validity } & \text { - Data triangulation: use of multiple types and sources of data } \\ & \text { - Embedded subcases included } \\ & \text { - Investigator triangulation: supervision, discussion and observer in place during } \\ & \text { - Pocus groups } \\ \text { - Propositions used in study } & \text { - Detailed description of the case recorded } \\ \text { - Findings of research integrated into the broader situational context } \\ \text { - Theoretical triangulation: findings of research integrated into the published } \\ \end{array}$

\section{4 | Data analysis}

Interviews were recorded and transcribed verbatim for analysis using an inductive approach (Bryman, 2008). Codes were developed in four stages, commencing with line by line coding to develop in vivo codes in participants own words and concluded with the generation of theoretical concepts. Data saturation was met when no new codes were developed during analysis (Saunders et al., 2018), data collection ceased, and case units were analysed individually and across units (Saldana, 2013). To provide a basis for idiographic generalization, codes and themes were analysed, contextualized and interpreted alongside a detailed description of the setting, the literature and the researcher's experience detailed in field notes. Strategies for case study rigour (Stake, 1995; Yin, 2009) are described in Table 2.

\section{3 | RESULTS}

Findings indicate that whilst all doctors, nurses and managers held patient safety as central to every decision made, each occupational group understood, experienced and managed patient safety differently; this created misunderstanding and conflict. As can be seen in reporting of qualitative research, the findings and discussion sections are presented together to include interpretation and discussion of meaning (Evans, 2007; Langdridge \& Hagger-Johnson, 2009).

\subsection{Safety occurs in a complex system}

Across the embedded units, safety was not perceived to be a simple concept where care was either safe or unsafe. Safety was often described where the risk of harm was dependent on the situation at that time. Participants recognized the interdependent and complex nature of the health care system suggesting: "there's so many layers in a big hospital system that it doesn't take much for the system to fall down because of one chink in the armour." (ICUSDR1). Clinicians and managers described conditions that culminated in a "tipping point" (ICUSDR1), where safety was compromised by competing demands. ED crowding and ICU capacity problems caused by "flow" (SM2, EDSRN 3, ICUSRN6) or "surge" (SM3, EDSRN1) created a "perfect storm" where the risk of harm was certain when "the workload, the pressure, the distractions, the competing priorities, the demands-a systemic problem-contributes to getting it wrong" (SM3). 
In order to manage safety, key organisational surveillance tools were used. Although there were similarities in how safety was perceived by clinicians working in ED and ICU, fundamental differences existed in the safety approaches and behaviours clinicians and managers applied. Managers valued safety systems that recorded, categorized and measured safety, Clinicians preferred systems that anticipated and responded to risk, characterized by vigilance.

\subsection{Safety surveillance}

Managers valued systems that recorded safety within a "clinical governance framework" (SM1) that categorized events and applied RCA to prevent reoccurrence. The incident reporting system was their key safety surveillance tool perceived as "the bottom line" (SM3) to generate safety culture. Contrastingly, front-line clinicians consistently described this system as "reactive" (ICUSDR3). It was not perceived to successfully mitigate risks in the complex dynamic environment clinicians experienced, with many concluding "I can't say (a harmful event) is not going to happen again" (EDSDR10). Indeed, decisions made by the NZ Health and Disability Commissioner (2018) indicate that reporting a preventable adverse event does not avoid the event reoccurring (e.g., 11HDCC01434; 13HDC01676). These perspectives reflect a persistent debate; traditional safety strategies are orientated towards understanding episodes of weakness and failure by understanding the cause of harmful incidents (Perrow, 1984; Reason, 1997). Alternatively, high reliability science and resilience engineering embrace proactively anticipating and remaining vigilant to risk (Weick \& Sutcliffe, 2001), appreciating knowledge that can be generated from any event, regardless of outcome (Flanagan, 1954; Hollnagel, Wears, \& Braithwaite, 2015).

Safety is traditionally defined as a state where as little as possible goes wrong ("Safety I") and assumes identifiable failures or malfunctions can be uncovered and resolved (Hollnagel et al., 2015). This perspective is consistent with international policy and approaches that managers favoured, that is, reporting concerns to management for resolution via top-down interventions (Westrum \& Adamski, 1999). Contrastingly, clinicians proposed RCA generated recommendations that "often lead to a drop-in safety outcome, because of the change in practice slowing the system down, introducing new error, people learning that new error." (ICUSDR2). The incident reporting system was viewed as bureaucratic, with clinicians suggesting safety is achieved by adapting to complex systemic conditions and individual patients in every day work. The clinician perspective acknowledges that safety outcomes are recognized as "emergent, rather than resultant," and safety is defined as the ability to succeed under varying conditions, or "Safety II" (Hollnagel et al., 2015, p. 23).

Clinicians viewed harm resulting from a hazard previously recorded as a near miss event as unacceptable, proposing this was common; "something happens then it's an adverse event, but actually it was a [near miss] for about the last 20." (SEDRN3). Near misses can occur up to 300 times more frequently than adverse events (Wolf \& Hughes, 2008), with harm from cumulative minor failures increasingly recognized as greater than harm from adverse events (Vincent
\& Amalberti, 2016). A focus on small repetitive events is congruent with the "mindful" approach prevalent in HROs where learning from previous, or potential failures is a proactive prevention strategy (Reason, 2000; Weick \& Sutcliffe, 2001). Managers indicated they "support a low threshold for reporting risks and are just as interested in near misses" (SM2), but this conflicted with the perceptions of clinicians that managers "don't even look at them" (SEDRN2) and that "it's easier to get resources to fix a rare problem, that has caused a single bad event than introduce a concept of improvement" (ICUSDR2). One possible explanation is managers who declined to participate indicated patient safety was "not part of the role" (field notes).

Incident reporting systems alone are not a valid, patient safety strategy (Leistikow, Mulder, Vesseur, \& Robben, 2016). Reason's famous "Swiss cheese model" is now out-dated (Reason, Hollnagel, \& Paries, 2006) and Hollnagel et al. (2015) propose learning from $\mathrm{RCA}$ is obsolete in complex environments where people and technology interact. Others conclude that a reactive top-down rational approach of imposing rules limits the proactive innovation required to maintain safety by supporting cultures of risk aversion and bureaucracy (Dekker, 2014; Hale \& Borys, 2013; Traynor, 1999).

Managers relied on risk registers to monitor and remain vigilant to safety risks; "if you've a level of risk that's not tolerable, we have a responsibility to raise this to the board." (SM2). Senior managers oversaw a complex, detailed process where assessment of clinical risk was undertaken in monthly meetings which did not include clinician experts from the embedded case units. Multiple risks, for example, clinical, financial and operational, were recorded together and assessment of patient safety was influenced by fiscal climate and the hospital board's tolerance to financial, political and reputational considerations. It has been noted that occupational groups classify risk differently (Dixon-Woods et al., 2009; Waring, 2005) and risks raised by clinicians are often downgraded by managers (Hardy, 2013). This risk management approach may explain the perception of managers paying "lip service" (EDSDR10) to safety issues and impacted safety culture; "patients need to be put first not targets, not negative outcomes, not bad publicity, the patient needs to be seen through all of that...unless you do that, you are going to have some difficulty with culture." (EDSDR10).

Such competing views about safety surveillance approaches resulted in a lack of consensus about safety issues for clinicians and managers. Clinicians used language such as "tension" (ICUSDR2) and "battle" (EDSRN1) when describing interactions about safety risks with managers in the organisation. Contrastingly, HRO theorists suggest "ambivalence builds resilience" within organisations which remain open to disparate perspectives (Weick \& Sutcliffe, 2001, p. 167). Health care professionals willing to listen to multiple perspectives may be better placed to mitigate immediate risk in practice. As resilience is increasingly conceptualized as a combination of reactive and proactive activities of adaptation, recovery and response (Macrae \& Draycott, 2016), health care systems underpinned by both Safety I and II approaches should be more successful. Research that illuminates how subcultures values, behaviours and actions differ will enhance our ability to nurture safety culture (Manion \& Smith, 2017). 


\section{3 | Vigilance and anticipation}

Key vigilant and anticipatory approaches were used to recognize and respond to complex safety risks; this was evident in data collection across all cases. Managers favoured tools vigilant to crowding and resource pressures including computerized systems that monitored staffing levels, care needs and occupancy. Clinicians valued speciality specific systems, developed by doctors, and the EWS system in ICU and triage in ED dominated clinical practice. Both tools monitor and are vigilant to the unpredictable nature of patients, anticipate deterioration in acute illness, prescribe a graded response and mobilize appropriate clinical expertise to the patient. International research findings, HDC case decisions and NZ policy suggest surveillance of a patient's clinical condition with tools such as triage and EWS can avoid preventable death in acute illness (National Confidential Inquiry into Patient Outcomes and Death, 2012; 13HDC00482, 05HDC11908). Such systems accommodate Vincent's (2006) assertion that individual patients are unpredictable, creating risks impossible to mitigate with complex rule-based approaches and HRO theory that encourages "deference to expertise" when dealing with complex problems (Weick \& Sutcliffe, 2001, p. 48).

The vigilant and anticipatory approaches health care professionals utilized are consistent with the view that safety is created when people adapt and respond to hazards in complex conditions, rather than trying to eliminate them (Hollnagel et al., 2015). A positive safety culture requires workable safety solutions that allow an organisation to achieve specified goals, whilst acknowledging hazards remain (Weick \& Sutcliffe, 2001). Our findings support proposals that successful health care systems are designed to support high functioning teams to recognize and respond to risk in their everyday work (Macrae \& Draycott, 2016).

\subsection{Firefighting: A strategy to manage risk}

Rather than working within pre-established sets of safety rules and norms, clinicians identified working outside "what is pre-defined" (EDSDR10) by organisational safety systems, as a necessary and proactive safety behaviour. Doctors described complex clinical situations and high clinical workloads in everyday work, suggesting "very few things present like we've been taught in a text book." (EDSDR10). Therefore, expertise in "risk stratification" (EDSDR5) to enable rapid, accurate patient assessment and mitigate the risk of "misdiagnosis" (EDSDR5) was highly valued.

"Firefighting" (ICUSDR5) skills were admired improvisation skills clinicians gained from experience and exposure to risk. Nurses claimed that informal processes or work-arounds maintained safety within a "background of chaos" (EDSRN2), insisting that "strategising around situations" (ICUSRN5) was an important facet of safety leadership. Informal leaders with "firefighting" skills were viewed as the "go to people" (EDRN4). Visible, experienced firefighters were trusted to know when to break or bend rules during anticipated and unanticipated safety events. Common examples of safety events "go to people" managed everyday included ED crowding, sub-optimal skill mix, MET calls and competition for ICU beds. Similarly, resilience engineers propose an important organisational resource is the knowledge and skills to detect emerging risks and provide a coordinated response, with shared expectations, assumptions and norms creating trust in high performing teams (Hollnagel, Woods, \& Leveson, 2006).

Managers utilized "firefighting" behaviours to predict and control limited resources but were clear that breaking organisational rules was an unsafe act: "You can have the frameworks there but if people aren't working to that and making it part of what they do every day then it's a waste of time." (SM2). Clinicians indicated rules, such as protocols or procedures, were usually cumbersome, difficult to access and apply in everyday work and failed to account for patient complexity. They proposed expertise in risk stratification as safer than working with multiple, competing rules that increased cognitive load and the potential for error. Senior clinicians wanted health care leaders to trust their clinical judgement, in a challenging situational context, over which they had minimal control:

It's not about winging it, it's about relying on your intuition and a bit of gut feeling about how far we can stretch, and what wouldn't be ideal if you were planning forward, but at that point in time is possibly your only solution. You can still make it safe by putting other things in place.

(ICUSRN2)

Although "firefighting" was viewed as a leadership attribute, it is similar to "patching" behaviour referred to in the safety literature (Perry, Wears, \& Fairbanks, 2012). Patching can encourage "muddling through" behaviour with unintended safety consequences by encouraging unwanted variation (Perry et al., 2012, p. 716). In this study, patching was reported to impact on safety, evident in ED where patients were re-triaged and treated in corridors, a recognized antecedent to harm (Ardagh \& Drew, 2015; Handel et al., 2010). Similarly, when several patients were competing for ICU beds, clinicians were forced to consider discharging patients at night to meet acute demand. With either of these situations, there is potential to decrease the safety of patients and clinicians (Laupland et al., 2011). The constant interplay between quality and efficiency that participants and field notes describe is well-recognized in acute care environments (Nugus \& Braithwaite, 2010; Perry et al., 2012) and can lead to "care rationing" choices (Nugus \& Braithwaite, 2010, p. 512) that impact safety, including "minimum standards (when one) can't afford gold plate" (SM2).

Whilst firefighting was recognized in this study, and in the literature, as an important and valuable skill to manage risk, it requires appropriate resources to mitigate the risk of harm. When the aspiration is to deliver patient care that is only "good enough" (Vincent \& Amalberti, 2016, p. 21), patients will be exposed to variation, poor standards and hazards. In unsafe organisational conditions, both patients and staff are harmed (Department of Health, 2013). Participants described essential safety building blocks, suggesting a resilient safety culture requires the right staff, skills, leadership and environment. A "buffer" (ICUSDR2) incorporating adequate staffing, manageable workloads and organisational capacity was identified 
as essential to enable the organisation and its people to respond to threats and opportunities and thereby "sustain required operations under both expected and unexpected conditions" (Hollnagel, Pariès, Woods, \& Wreathall, 2010).

\section{5 | Limitations}

A limitation of this study was the small number of senior managers who participated. To address this, we examined health care literature to determine that views shared were representative. We examined only one NZ health care organisation and findings are limited to high-hazard environments with similar characteristics. Replication is required in other non-specialized areas where different safety challenges exist.

\section{4 | CONCLUSION}

Patient safety is a core value clinicians and managers describe, although multiple perspectives exist regarding how risks are identified, operationalized and mitigated. Failing to account for differences of interconnected subcultures creates conflict and erodes trust. A deeper understanding of the complex situational context of health care environments is required with health care policy and leadership that acknowledges diversity to promote safety approaches that build trust and nurture safety culture.

\section{5 | IMPLICATIONS FOR NURSING MANAGEMENT}

There is growing recognition of the importance of safety culture in organisations with significant research exploring health professionals' understanding of patient safety. Research and policy work in this area have traditionally questioned whether health professionals are engaged with the patient safety movement with a resulting lack of consensus regarding how patient safety is conceived and operationalized. Doctors, nurses and senior managers within the complex environment of acute hospitals hold different perspectives on safety; these have informed development of unique, context-specific and disciplinary-specific safety approaches that mirror strategies favoured by HROs and resilience engineers.

A collaborative approach to safety is required to build trust and nurture safety culture. Nurse managers can support this by creating opportunities for open dialogue and embracing an interdisciplinary approach. Different perspectives must be acknowledged so a more refined understanding and approach to safety is developed within and across occupational groups. Nurse managers must appreciate safety strategies that acknowledge the important human contribution to safety and advocate for the resources required to build resilient teams that can adapt to complexity in their everyday work context. The challenge this presents cannot be underestimated when the international approach is dominated by traditional safety approaches, hierarchies and efficiency drives.

\section{ACKNOWLEDGEMENTS}

We thank the doctors, nurses and managers who gave their time to contribute to the study. This study reports the findings of a student thesis for the qualification of Masters in Healthcare Research, Victoria University of Wellington.

\section{ETHICAL APPROVAL}

Ethical approval was given by the Victoria University of Wellington Human Ethics Committee (ref. no. 21386).

\section{ORCID}

Jo Wailling (iD http://orcid.org/0000-0002-4430-2866

Brian Robinson (iD https://orcid.org/0000-0001-5159-2702

Maureen Coombs (iD https://orcid.org/0000-0001-6674-0093

\section{REFERENCES}

Ardagh, M., \& Drew, L. (2015). What have five years of the shorter stays in ED health target done to us? The New Zealand Medical Journal, 218(1421), 47-54

Atkin, L., Slone, D., Bruyneel, L., Van den Heede, K., Griffiths, P., Busse, R., ... Sermeus, W.; for the RNZCAST consortium (2014). Nurse staffing and education and hospital mortality in nine European countries: A retrospective observational study. The Lancet, 383(9931), 1824-1830.

Braithwaite, J., Herkes, J., Ludlow, K., Testa, L., \& Lamprell, G. (2017) Association between organisational and workplace cultures, and patient outcomes: Systematic review. British Medical Journal Open, 7(11), e017708.

Bryman, A. (2008). Social research methods (3rd ed.). Oxford, UK: Oxford University Press.

Carayon, P. (2012). Human factors and ergonomics in healthcare and patient safety. Boca Ranton, FL: CRC Press.

Dekker, S. (2014). The bureaucratization of safety. Safety Science, 70, 348-357. https://doi.org/10.1016/j.ssci.2014.07.015

Department of Health. Francis, R. chair (2013). Report of the Mid Staffordshire NHS Foundation Trust Public Inquiry. London, UK: Crown Copyright.

Dixon-Woods, M., Suokas, A., \& Tarrent, C. (2009). An ethnographic study of classifying and accounting for risk at the sharp end of medical wards. Social Science and Medicine, 69, 362-369. https://doi. org/10.1016/j.socscimed.2009.05.025

Evans, J. (2007). Your psychology project: The essential guide. London, UK: Sage Publications.

Flanagan, J. (1954). The critical incident technique. Psychological Bulletin, 51(4), 327-358.

Hale, A., \& Borys, D. (2013). Working to rule, or working safely? Part 1: A state of the art review. Safety Science, 55, 207-221. https://doi. org/10.1016/j.ssci.2012.05.011

Handel, D., Hilton, J., Ward, M., Rabin, E., Zwemer, F., \& Pines, J. (2010). Emergency department throughput, crowding, and financial outcomes for hospitals. Academic Emergency Medicine, 17, 840-847. https://doi.org/10.1111/(ISSN)1553-2712

Hardy, L. (2013). How do district health boards respond to and use the serious and sentinel event report? Thesis, Masters of Public Health, University of Otago, Dunedin, New Zealand. Retrieved from https://ourarchive.otago.ac.nz/bitstream/handle/10523/5059/ HardyLiviaN2014MPH.pdf?sequence=1 
Health and Disability Commissioner (2018). Decisions. Retrieved from https://www.hdc.org.nz/decisions/

Health Quality Safety Commission (2017). National adverse events policy. Wellington, New Zealand: HQSC.

Health Quality Safety Commission (2018). AboutUs. Retrieved from https:// www.hqsc.govt.nz/about-us/HealthQualitySafety Commission

Hollnagel, E., Pariès, J., Woods, D. D., \& Wreathall, J. (Eds.). (2010). Resilience engineering perspectives: Resilience engineering in practice. Farnham, UK: Ashgate.

Hollnagel, E., Wears, R., \& Braithwaite, J. (2015). From safety-I to safety-II: A white paper. The Resilient Healthcare Net: University of Southern Denmark, University of Florida and Macquarie University, Australia.

Hollnagel, E., Woods, D. D., \& Leveson, N. C. (Eds.) (2006). Resilience engineering: Concepts and precepts. Aldershot, UK: Ashgate.

Institute of Healthcare Improvement (2016). Develop a culture of safety. Retrieved from http://www.ihi.org/resources/Pages/Changes/ DevelopaCultureofSafety.aspx

Kohn, L., Corrigan, J., \& Donaldson, M. (Eds.). (2000). To err is human: Building a safer health system. Washington, DC: National Academies Press.

Langdridge, D., \& Hagger-Johnson, G. (2009). Introduction to research methods and data analysis in psychology (2nd ed.). Harlow, UK: Pearson Education.

Laupland, K. B., Misset, B., Souweine, B., Tabahj, A., Azoulay, E., Goldgran-Toledano, D., ... Timsit, J. F. (2011). Mortality associated with timing of admission to and discharge from ICU: A retrospective cohort study. BMC Health Services Research, 11, 321. https://doi. org/10.1186/1472-6963-11-321

Leistikow, I., Mulder, S., Vesseur, J., \& Robben, P. (2016). Learning from incidents in healthcare: The journey, not the arrival, matters. BMJ Quality Safety, 26, 252-256.

Macrae, C., \& Draycott, T. (2016). Delivering high reliability in maternity care: In situ simulation as a source of organisational resilience. Safety Science. Retrieved from http://www.sciencedirect.com/science/ article/pii/S0925753516304349.

Manion, R., \& Smith, J. (2017). Hospital culture and clinical performance: Where next? British Medical Journal Quality Safety, 27, 179-181.

Martin, G., Mason, D., Lovelock, K., Cumming, J., \& Hider, P. (2015). Health professionals' perceptions of quality survey: A report for the Health Quality and Safety Commission. Wellington, New Zealand: HQSC.

Ministry of Health (2018). Healthcare targets. Retrieved from https:// www.health.govt.nz/new-zealand-health-system/health-targets

National Confidential Inquiry into Patient Outcomes and Death (2012). Time to intervene: A review of patients who underwent CPR as a result of an in hospital cardiorespiratory arrest. London, UK: NCPOD.

National Patient Safety Foundation (2015). Free from harm: Accelerating patient safety improvement fifteen years after 'To err is human'. Boston, MA: NPSF.

National Patient Safety Foundation (2017). Call to action: Preventable healthcare harm is a public health crisis and patient safety requires a coordinated public heath response. Boston, MA: NPSF.

Nugus, P., \& Braithwaite, J. (2010). The dynamic interaction of quality and efficiency in the ED: Squaring the circle? Social Science and Medicine, 70, 511-517. https://doi.org/10.1016/j.socscimed.2009.11.001

Perrow, C. (1984). Normal accidents: Living with high-risk technologies. Princeton, NJ: Princeton University Press.

Perry, S. J., Wears, R. L., \& Fairbanks, R. J. (2012). Human factors and ergonomics in the emergency department. In P. Carayon (Ed.), Human factors and ergonomics in healthcare and patient safety (pp. 709-723). Boca Ranton, FL: CRC Press.

Queensland Public Hospitals Commission of Inquiry, \& Davies, G. (2005). Queensland public hospitals commission of inquiry into Bundaberg hospital. Brisbane, Australia. Queensland Public Hospitals Commission of Inquiry.

Reason, J. (1997). Managing the risks of organisational accidents. Aldershot, UK: Ashgate publishing.
Reason, J. (2000). Human error: Models and management. Western Journal of Medicine, 172(6), 393-396. https://doi.org/10.1136/ ewjm.172.6.393

Reason, J., Hollnagel, E., \& Paries, J. (2006). Revisiting the "swiss cheese" model of accidents. Journal of Clinical Engineering, 27, 110-115.

Rubin, H., \& Rubin, I. (2012). Qualitative interviewing: The art of hearing data (3rd ed.). Thousand Oaks, CA: Sage Publications.

Saldana, J. (2013). The coding manual for qualitative researchers (6th ed.). Los Angeles, CA: Sage Publications.

Saunders, B., Sim., J., Kingstone., T., Baker., S., Waterfield, J., Bartlam., B., ... Jinks, C. (2018). Saturation in qualitative research: Exploring its conceptualisation and operationalisation. Quality Quantity, 52(4), 1893-1907. https://doi.org/10.1007/s11135-017-0574-8

Scott, A., Jeon, S. H., Joyce, C. M., Humphreys, J. S., Kalb, G., Witt, J., $\&$ Leahy, A. (2011). A randomised trial and economic evaluation of the effect of response mode on response rate, response bias, and item non-response in a survey of doctors. BMC Medical Research Methodology, 11(1), 126. https://doi.org/10.1186/1471-2288-11-126

Stake, R. (1995). The art of care study research. Thousand Oaks, CA: SAGE Publications.

Stake, R. (2005). Qualitative case studies. In K. Norman \& Y. Denzin(Eds.), The sage handbook of qualitative research (3rd ed., pp. 443-466). Thousand Oaks, CA: SAGE publications.

Sutcliffe, K. (2011). High Reliability Organisations (HROs). Best Practice and Research Clinical Anesthesiology, 25, 133-144.

Traynor, M. (1999). Managerialism and nursing beyond oppression and profession. London, UK: Routledge.

Vaugh, V., Saint, S., Krein, S., Forman, J., Meddings, J., Ameling, J., ... Chopra, V. (2018). Characteristics of healthcare organisations struggling to improve quality: Results from a systematic review of qualitative studies. British Medical Journal Quality Safety, 0, 1-11. https://doi. org/10.1136/bmjqs-2017-007573

Vincent, C. (2006). Patient safety. London, UK: Elsevier.

Vincent, C., \& Amalberti, R. (2016). Safer healthcare: Strategies for the real world. Springer. Open access. Retrieved from https://www.springer. com/gp/book/9783319255576

Waring, J. (2005). Beyond Blame: Cultural barriers to medical incident reporting. Social Science and Medicine, 60, 1927-1935. https://doi. org/10.1016/j.socscimed.2004.08.055

Weick, K., \& Sutcliffe, K. (2001). Managing the unexpected: Assuring high performance in an age of complexity. San Francisco, CA: Jossey Bass.

Westrum, R., \& Adamski, A. (1999). Organizational factors associated with safety and mission success in aviation environments. In D. J. Garland, J. A. Wise, \& V. D. Hopkins (Eds.), Aviation human factors (pp. 67-104). Hillsdale, MI: Lawrence Erlbaum.

Wolf, Z., \& Hughes, R. (2008). Error reporting and disclosure. In R. Hughes (Ed.), Patient safety and quality: An evidence-based handbook for nurses (Chapter 35, pp. 1-47). Rockville, MD: Agency for Healthcare Research and Quality.

World Health Organisation (2018). Ten facts on patient safety. Retrieved from http://www.who.int/features/factfiles/patient_safety/en/

Ybema, S., Yanow, D., Wels, H., \& Kamsteeg, F. (2009). Organisational ethnography: Studying the complexity of everyday life. London, UK: Sage Publications. https://doi.org/10.4135/9781446278925

Yin, R. (2009). Case study research design and methods (4th ed.). Thousand Oaks, CA: Sage Publications.

How to cite this article: Wailling J, Robinson B, Coombs M. Surveillance, anticipation and firefighting: Perspectives of patient safety from a New Zealand case study. J Nurs Manag. 2019;00:1-7. https://doi.org/10.1111/jonm.12732 